\title{
Multiple drilling combined with simvastatin versus multiple drilling alone for the treatment of avascular osteonecrosis of the femoral head: 3-year follow-up study
}

\author{
Han Yin, Zhenfeng Yuan ${ }^{*}$ and Dawei Wang
}

\begin{abstract}
Background: Multiple small drilling for core decompression is widely used to preserve the femoral head in patients with avascular necrosis of the femoral head (ANFH). Nevertheless, the clinical outcome remains controversial. Simvastatin has been demonstrated to promote bone formation and reduce bone adsorption. The purpose of this study was to determine whether simvastatin enhanced the effect of multiple decompressions in preventing progression of ANFH and to identify independent risk factors associated with poor results.

Methods: We retrospectively analyzed 58 hips in 36 patients, with a follow-up of 36 months. 20 patients (32 hips) underwent multiple drilling combined with simvastatin treatment (SIM group); 16 patients (26 hips) underwent multiple drilling alone (MD group). We defined clinical failure as a requirement for subsequent hip surgery or Harris Hip Score $<75$. New occurrence of collapse or increased collapse $>2 \mathrm{~mm}$ on plain radiographs was defined as radiological failure.

Results: Successful clinical results were achieved in 27 of 32 hips (84\%) in the SIM group compared with 15 of 26 hips $(58 \%)$ in the $M D$ group $(\mathrm{OR}=0.2, \mathrm{Cl}(0.1,0.6),. P=0.032)$. Successful radiological results were achieved in 27 of 32 hips (84 \%) in the SIM group and in 16 of 26 hips (61.5\%) in the MD group $(P=0.048)$. Body mass index, disease stage and location of lesion were independent prognostic factors for overall survival.
\end{abstract}

Conclusions: We believe that simvastatin could enhance the effects of multiple decompressions in preventing progression of ANFH and reducing the risk of femoral head collapse.

Keywords: Femoral head necrosis, Core decompression, Multiple decompression, Simvastatin, Preservation of hip

\section{Background}

Avascular necrosis of the femoral head (ANFH) is a common cause of hip disability in relatively young, active people between 20 and 40 years of age. It may progress to collapse of the femoral head if left untreated [1] and $80 \%$ of these patients will require total hip arthroplasty (THA) [2]. Preservation of the femoral head is the ultimate goal in the treatment of ANFH [3]. Although many treatment methods for early stage ANFH, including electrical stimulation, core decompression, rotational osteotomy and

\footnotetext{
*Correspondence: lygkyzf@163.com
Department of Orthopaedics, Liaocheng People's Hospital and Liaocheng

* Correspondence: lygkyzf@163.com Clinical School of Taishan Medical University, No. 67, Dongchang Road, Liaocheng, Shandong, China
}

(c) 2016 The Author(s). Open Access This article is distributed under the terms of the Creative Commons Attribution 4.0 International License (http://creativecommons.org/licenses/by/4.0/), which permits unrestricted use, distribution, and reproduction in any medium, provided you give appropriate credit to the original author(s) and the source, provide a link to the Creative Commons license, and indicate if changes were made. The Creative Commons Public Domain Dedication waiver (http://creativecommons.org/publicdomain/zero/1.0/) applies to the data made available in this article, unless otherwise stated.

nonvascularized and vascularized bone grafting, have been proposed based on patient age, symptoms, stage, and/or medical status, the orthopedic community has not yet adopted a uniform treatment algorithm [4].

Core decompression, which is thought to decrease intramedullary pressure, encourage revascularization and relieve pain, is a widely accepted procedure for early stage ANFH [5, 6]. Although core decompression and core decompression in combination with bone graft, bone marrow injection, platelet-rich plasma injection or mesenchymal stem cell injection have achieved excellent clinical outcomes in the treatment of ANFH [2, 5, 7, 8], some reports note complication rates as high as 10-15\% [8-11]. Seeking a minimally invasive, safe and effective 
treatment for ANFH, Kim et al. proposed the use of multiple small drilling for core decompression at the annual Association Internationale de Recherche sur la Circulation Osseuse (ARCO) meeting in 2003. They reported a lower rate of collapse (14.3\%) compared with traditional core decompression methods (45\%) 3 years after surgery [12].

Statins have been demonstrated to reduce the risk of corticosteroid-induced ANFH through improving disturbances of lipid metabolism [13-16]. In addition, it has been reported that statins can increase the expression of bone morphogenetic protein 2 (BMP-2) mRNA in osteoblasts, promote bone formation [17, 18] and decrease the formation and activity of osteoclasts, inhibiting bone resorption [19, 20]. Clinical studies have discovered that statins can reduce fracture risk [21], increase bone mineral density [22] and promote the expression of biochemical markers of bone metabolism to serve as a tool for the diagnosis of osteoporosis [23].

The purpose of the present study was to: (1) determine whether simvastatin can enhance the effects of multiple decompressions in preventing the progression of ANFH and reducing the risk of femoral head collapse; and (2) identify independent risk factors associated with poor results.

\section{Methods}

Multiple small-diameter drilling was performed by one of us (Zhenfeng Yuan) between April 2011 and June 2012 in 39 patients (64 hips) at the same institution for the treatment of non-traumatic osteonecrosis of the femoral head. Of these patients, 21 (34 hips) received simvastatin after the procedure. Eighteen patients (30 hips) who refused subsequent treatment with simvastatin were taken as controls. Patients in the MD group underwent core decompression with multiple small-diameter drilling. Patients in the SIM group underwent multiple drilling combined with oral simvastatin, $20 \mathrm{mg}$ per day for 12 months beginning on the day after the drilling procedure. In the MD group, two patients (four hips) were lost to follow-up; therefore, 16 patients (26 hips) were available for study. In the SIM group, one patient (two hips) was lost to follow-up; therefore, 20 patients (32 hips) were available for study (Fig. 1). Observations were truncated 36 months postoperatively to permit statistical comparison between the two groups. This study was approved by the ethics committee of Liaocheng People's Hospital and informed consent was obtained from all individual participants included in the study.

Osteonecrosis of the femoral head was diagnosed if magnetic resonance imaging (MRI) (coronal and sagittal) revealed the following: belt-shaped or circular low intensity signals surrounded by high intensity signals in the outer area on short tau inversion; or a high intensity area surrounded by belt-shaped or circular low intensity signals within the femoral head on T1-weighted images [24]. The patients were classified according to the ARCO system [25]. Patients were eligible for inclusion in the study if they were older than 18 years, had hip pain and had ARCO stage I, II or IIIA ANFH. Patients were excluded from the study if they had ARCO stage IIIB, IIIC or IV ANFH. The procedure was not performed on patients older than 60 years.

The largest anteroposterior diameter of the head (R), the longest anteroposterior length of the necrotic lesion

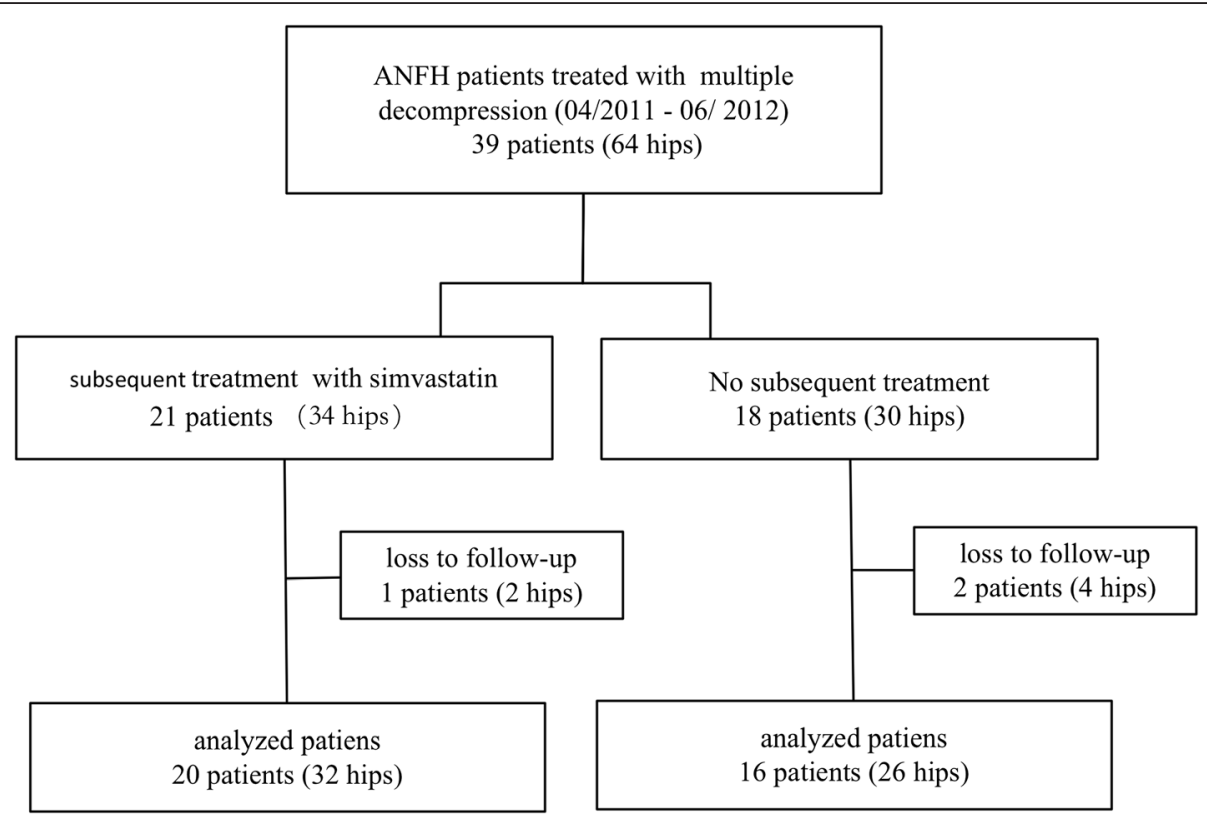

Fig. 1 Flow diagram of patient selection. ANFH, avascular necrosis of femoral head 
(A) and the longest mediolateral length of the necrotic lesion (B) were measured on axial slices on MRI. The extent of the necrotic portion was calculated by the equation: percentage of necrotic lesion $=\left\{(\mathrm{A} \times \mathrm{B}) / \mathrm{R}^{2}\right\} \times 100$. This method has a more acceptable accuracy and is reasonably repeatable compared with other methods [26]. All hips were assessed using this method, with necrotic portions greater than $30 \%$ considered large lesions, 15-30\% medium lesions and less than $15 \%$ small lesions. The location of the necrotic lesion was classified as A, B, C1 or C2 according to the classification developed by the Specific Disease Investigation Committee under the auspices of the Japanese Ministry of Health, Labor and Welfare [27]. Three experienced radiologists reviewed all MRI scans and plain radiographs together in a blinded fashion.

Before the procedure, details of the patient's age, gender and body mass index (BMI), duration of symptoms, cause of ANFH, unilateral or bilateral involvement, ARCO stage, lesion size, location of lesion, Harris Hip Score (HHS) and visual analog scale (VAS) pain score were recorded (Table 1).

Patients were followed-up 1, 3, 6, 9, 12, 24 and 36 months after the procedure. In addition, they received a follow-up visit whenever they were unwell. Follow-up took the form of outpatient visits. Examinations included joint pain, function and range of motion. HHS and VAS pain score were recorded. Plain radiographs (anteroposterior and frog lateral view) and MRI scans of both hips were obtained at scheduled follow-up times. The primary outcomes of the study were clinical and radiological failure. Clinical failure was defined as HHS $<75$ points or a requirement for subsequent hip surgery such as bone grafting, osteotomy or hip replacement. New occurrence of collapse or increased collapse of greater than $2 \mathrm{~mm}$ on plain radiographs during follow-up was defined as radiological failure [28, 29].

For the drilling procedure, patients were placed in the supine position on a fracture table. A C-arm fluoroscope was draped with a sterile sleeve and positioned over the hip region to enable an anteroposterior view. After the position of the femoral head had been marked and the hip draped, a $3.0 \mathrm{~mm}$ Steinman pin was inserted percutaneously under fluoroscopic guidance. The pin was inserted into the femoral head at the site of the lesion. Anteroposterior and lateral fluoroscopic views were necessary while advancing the pin to ensure that it remained in the medullary canal of the femoral neck. Depending on lesion size, each femoral head was drilled three to six times. The wound was closed using a simple bandage without suture.

Patients who had undergone unilateral drilling were advised to use two crutches when walking for 6 weeks after the procedure. Two crutches when walking for
Table 1 Baseline patient characteristics

\begin{tabular}{|c|c|c|c|c|}
\hline Characteristic & Total & SIM Group & MD Group & $P$ value \\
\hline \multicolumn{4}{|l|}{ Sex } & \multirow[t]{4}{*}{0.479} \\
\hline Men & $26(72)$ & $13(65)$ & $13(81)$ & \\
\hline Women & $10(28)$ & $7(35)$ & $3(19)$ & \\
\hline \multicolumn{4}{|c|}{ Age (years) } & \\
\hline Mean & $41.6 \pm 1.1$ & $39.1 \pm 1.4$ & $44.7 \pm 1.6$ & 0.010 \\
\hline Median & $42(37.8-48)$ & $40(36-44.5)$ & $45(41.8-49)$ & $0.003^{\mathrm{a}}$ \\
\hline \multicolumn{5}{|c|}{$\mathrm{BMI}\left(\mathrm{kg} / \mathrm{m}^{2}\right)$} \\
\hline Mean & $25.6 \pm 0.3$ & $25.6 \pm 0.4$ & $25.6 \pm 0.6$ & 0.958 \\
\hline Median & $25.2(23.7-26.7)$ & $24.7(23.5-26.7)$ & $25.3(23.7-26.5)$ & $0.833^{\mathrm{a}}$ \\
\hline $\begin{array}{l}\text { Duration of } \\
\text { symptoms } \\
\text { (months) }\end{array}$ & $3(1-6.5)$ & $3(1.13-8)$ & $2.5(1-5.25)$ & 0.354 \\
\hline \multicolumn{4}{|l|}{ Laterality } & \multirow[t]{3}{*}{0.878} \\
\hline Unilateral & $14(39)$ & $8(40)$ & $6(37)$ & \\
\hline Bilateral & $22(61)$ & $12(60)$ & $10(63)$ & \\
\hline Left: Right & $29: 29$ & $16: 16$ & 13:13 & 1.000 \\
\hline \multicolumn{4}{|l|}{$\begin{array}{l}\text { Cause of } \\
\text { ANFH }\end{array}$} & \multirow[t]{4}{*}{$0.640^{b}$} \\
\hline Steroids & $6(10)$ & $3(9)$ & $3(11)$ & \\
\hline Alcohol & $24(41)$ & $15(47)$ & $9(35)$ & \\
\hline Idiopathic & 28() & $14(44)$ & $14(54)$ & \\
\hline \multicolumn{4}{|l|}{ ARCO stage } & \multirow[t]{6}{*}{$0.108^{b}$} \\
\hline I & $10(17)$ & $3(9)$ & $7(27)$ & \\
\hline$\| \mathrm{a}$ & $2(3)$ & $1(3)$ & $1(4)$ & \\
\hline$\| \mathrm{b}$ & $12(21)$ & $10(32)$ & $2(8)$ & \\
\hline$\| c$ & $29(50)$ & $16(50)$ & $13(50)$ & \\
\hline Illa & $5(9)$ & $2(6)$ & $3(11)$ & \\
\hline \multicolumn{4}{|l|}{ Lesion size } & \multirow[t]{4}{*}{$0.021^{b}$} \\
\hline Small & $8(14)$ & $2(6)$ & $6(23)$ & \\
\hline Medium & $13(22)$ & $11(34)$ & $2(8)$ & \\
\hline Large & $37(64)$ & $19(60)$ & $18(69)$ & \\
\hline \multicolumn{4}{|l|}{$\begin{array}{l}\text { Lesion } \\
\text { location }\end{array}$} & \multirow[t]{5}{*}{$0.770^{b}$} \\
\hline A & $2(3)$ & $2(6)$ & $0(0)$ & \\
\hline$B$ & $26(45)$ & $14(44)$ & $12(46)$ & \\
\hline $\mathrm{C} 1$ & $15(26)$ & $8(25)$ & $7(27)$ & \\
\hline $\mathrm{C} 2$ & $15(26)$ & $8(25)$ & $7(27)$ & \\
\hline \multicolumn{4}{|l|}{ Hydrarthrosis } & \multirow[t]{3}{*}{0.985} \\
\hline Yes & $20(34)$ & $11(34)$ & $9(25)$ & \\
\hline No & $38(66)$ & $21(66)$ & $17(75)$ & \\
\hline VAS & $6.1 \pm 1.2$ & $6.2 \pm 1.4$ & $6.0 \pm 1.1$ & 0.546 \\
\hline HSS score & $66 \pm 5.2$ & $65 \pm 5.7$ & $68 \pm 4.5$ & 0.767 \\
\hline
\end{tabular}

${ }^{a}$ Determined with the Mann-Whitney $U$ test

${ }^{\text {b}}$ Determined with the Fisher exact test 
12 weeks were advised for patients who had undergone a bilateral procedure. Patients were allowed to engage in physical activities and sports 12 months after surgery. No further rehabilitation program was implemented [28].

Statistical analysis of the data was performed using SPSS version 18.0 for Windows (IBM, Armonk, NY, USA). Baseline characteristics were presented using descriptive statistics. The chi-square test was used to compare nominal data. The $t$-test or Mann-Whitney $U$ test was used to compare metric data. Univariate analyses were performed using the chi-square test. Variables with a $P$ value of less than 0.10 on univariate analysis were entered into multivariate analysis. Causes of ANFH were also entered into multivariate analysis. Multivariate analysis was performed using a logistic proportional hazards regression model. Because of the multicollinearity between ARCO stage and lesion size, models were fitted using the forward conditional procedure. All statistical assessments were two-sided and evaluated at the 0.05 level of statistical significance.

\section{Results}

Detailed baseline patient characteristics are shown in Table 1. Patients in the SIM group were younger (mean age 40 years, range 36-44.5) than those in the MD group (mean age 45 years, range $41.8-49)(P=0.003)$. There were more patients with medium or large necrotic lesions in the SIM group than in the MD group $(P=0.021)$.

At 36 months follow-up, the proportion of successful clinical results was significantly higher in the SIM group compared with the MD group $(P=0.024)$. Successful clinical results were achieved in 27 of 32 hips (84 \%) in the SIM group (Fig. 2). Of the five hips (16\%) that were considered clinical failures, two underwent THA because of secondary degenerative arthritis 18 months and 26 months after the drilling procedure; the other three had not undergone any further reconstructive procedures at the time of the last follow-up visit. In the MD group, successful clinical results were achieved in 15 of 26 hips (58\%). Of those that were clinical failures, seven hips underwent THA because of secondary degenerative

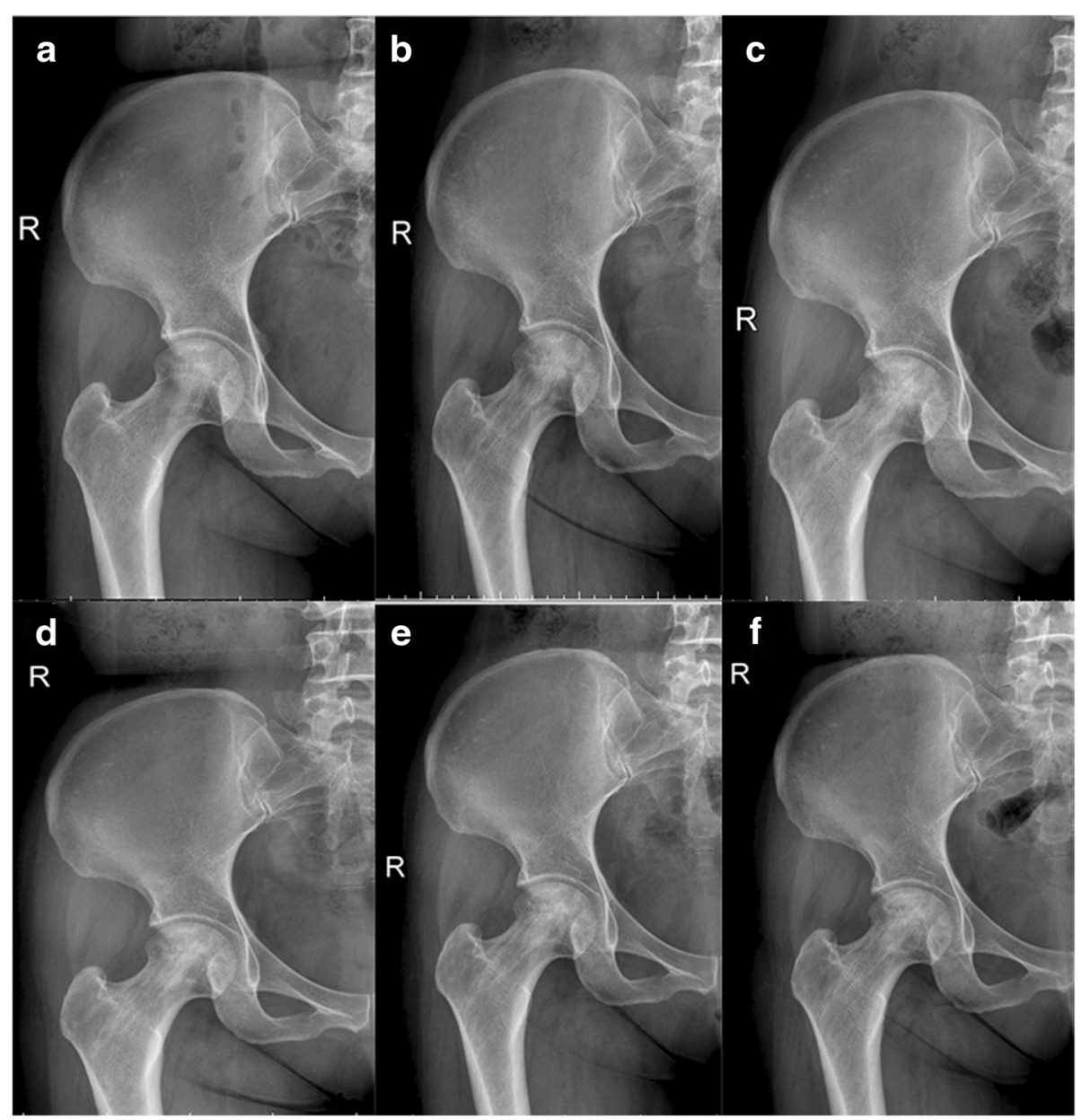

Fig. 2 Representative radiographs from SIM group. a Preoperative; b-f 3, 9, 12, 24 and 36 months postoperatively 
arthritis at a mean of 14 months (range 6-26) after the procedure, one underwent vascularized fibular grafting at 15 months and the remaining three had not undergone any further reconstructive procedures at the last followup. The SIM group had a better radiological outcome than the MD group $(P=0.048)$. Successful radiological results were achieved in 27 of 32 hips (84\%) in the SIM group and in 16 hips (61.5\%) in the MD group (Table 2).

There was a significant difference between the preoperative and last follow-up HHS in both groups and a significant difference was observed between the groups in the last follow-up HHS $(88.6 \pm 7.3$ vs $79.4 \pm 5.3, P=0.034)$. A significant difference was observed between the SIM group $(2.4 \pm 0.8)$ and the MD group $(3.6 \pm 0.6)$ in the last follow-up VAS score $(P=0.014)$.

The procedure was a clinical success in nine of the 10 stage I hips (90\%), both stage IIa (100\%), all 12 stage IIb (100\%), 18 of the 29 stage IIc $(62.1 \%)$ and one of the five stage IIIa (20\%). When the hips were divided into earlier stage (ARCO stage I, IIa or IIb) and later stage (ARCO stage IIc or IIIa), 23 of the 24 (96\%) earlier stage hips had successful clinical results compared with 19 of the $34(56 \%)$ later stage hips $(P=0.001)$ (Table 2). When the hips were stratified by lesion size, all $(100 \%)$ hips with a small or medium necrotic lesion had successful clinical results compared with only 21 of the 37 (57 \%) hips with a large lesion $(P=0.007)$ (Table 2). Among hips (52) with non-corticosteroid-induced ANFH, 24 of the 29 (82.8 \%) hips in the SIM group had successful clinical results compared with 13 of the 26 (50\%) hips in the MD group $(P=0.038)$ (Table 2).

On univariate analysis, lesions located medially, low BMI and no hydrarthrosis were associated with significantly better clinical outcome $(P=0.029, P=0.019$ and $P=0.031$ ) (Table 2). Treatment type, ARCO stage, necrotic lesion size, location of lesion, BMI and hydrarthrosis were included in multivariate analysis. Cause of ANFH (corticosteroids, alcohol or idiopathic) has been considered a predictor of clinical success in many studies $[8,29]$; therefore, we also included cause of ANFH in our multivariate analysis, although it was not a predictor of clinical success on univariate analysis in our patient population. On multivariate analysis, treatment type, BMI, ARCO stage and lesion location were identified as independent prognostic factors for overall survival (Table 3).

There were no superficial infections, deep infections, femoral neck fractures, subtrochanteric fractures, heterotopic ossifications, hematomas or other complications associated with the procedure in either group. No patient has simvastatin-related complications.

\section{Discussion}

To the best of our knowledge, this is the first study comparing the beneficial effects on ANFH of systemic
Table 2 Univariate analysis of prognostic factors for clinical success rate

\begin{tabular}{|c|c|c|c|c|}
\hline & Total & Success & Failure & $P$ value \\
\hline Treatment & & & & 0.024 \\
\hline SIM & 32 & $27(84)$ & $5(16)$ & \\
\hline $\mathrm{MD}$ & 26 & $15(58)$ & $11(42)$ & \\
\hline Age (years) & & & & 0.443 \\
\hline$<40$ & 17 & $14(82)$ & $3(18)$ & \\
\hline$>40$ & 41 & $28(68)$ & $13(32)$ & \\
\hline Sex & & & & 0.955 \\
\hline Men & 42 & $31(74)$ & $11(26)$ & \\
\hline Women & 16 & $11(69)$ & $5(31)$ & \\
\hline BMI (kg/m2) & & & & 0.019 \\
\hline$<25$ & 29 & $25(86)$ & $4(14)$ & \\
\hline$\geq 25$ & 29 & $17(59)$ & $12(41)$ & \\
\hline $\begin{array}{l}\text { Duration of symptoms } \\
\text { (months) }\end{array}$ & & & & 0.951 \\
\hline$<3$ & 25 & $18(72)$ & $7(28)$ & \\
\hline$>3$ & 33 & $24(73)$ & $9(27)$ & \\
\hline Laterality & & & & 1.000 \\
\hline Unilateral & 14 & $10(71)$ & $4(29)$ & \\
\hline Bilateral & 44 & $32(73)$ & $12(27)$ & \\
\hline Cause of ANFH & & & & $0.764^{a}$ \\
\hline Steroids & 6 & $5(83)$ & $1(17)$ & \\
\hline Alcohol & 24 & $18(75)$ & $6(25)$ & \\
\hline Idiopathic & 28 & $19(68)$ & $9(32)$ & \\
\hline ARCO stage & & & & 0.001 \\
\hline I, $\|\mathrm{a},\| \mathrm{b}$ & 24 & $23(96)$ & $1(4)$ & \\
\hline$\|c\| l \mid a$, & 34 & $19(56)$ & $15(44)$ & \\
\hline Lesion size & & & & $0.007^{\mathrm{a}}$ \\
\hline Small + Medium & 21 & $21(100)$ & $0(0)$ & \\
\hline Large & 37 & $21(57)$ & $16(43)$ & \\
\hline Lesion location & & & & 0.029 \\
\hline$A, B$ & 28 & $24(86)$ & $4(14)$ & \\
\hline $\mathrm{C} 1, \mathrm{C} 2$ & 30 & $18(60)$ & $12(40)$ & \\
\hline Hydrarthrosis & & & & 0.031 \\
\hline Yes & 20 & $11(55)$ & $9(45)$ & \\
\hline No & 38 & $31(82)$ & $7(18)$ & \\
\hline
\end{tabular}

${ }^{a}$ Determined with the Fisher exact test

Percentages are in parentheses

simvastatin following core decompression by multiple small-diameter drilling. Our preliminary results show that multiple small-diameter drilling combined with systemic simvastatin was better than multiple small-diameter drilling alone.

Given the relatively young age of patients at the time of presentation and the fact that the currently available prostheses may not be used for a lifetime, the treatment 
Table 3 Multivariate analysis of prognostic factors for clinical success rate

\begin{tabular}{llr}
\hline & Odd ratio $^{\mathrm{a}}$ & $P$ value $^{\mathrm{b}}$ \\
\hline Treatment & 1 & 0.032 \\
MD & $0.2(0.1,0.6)$ & \\
BMI (kg/m2) & & 0.014 \\
$<25$ & 1 & \\
$\geq 25$ & $20.9(1.9,234.1)$ & \\
ARCO stage & & \\
I, II a, II b & 1 & 0.006 \\
II c,Ill a & $32.1(3.4,530.4)$ & \\
Lesion location & & \\
A, B & 1 & \\
C1, C2 & $17.4(1.6,185.9)$ & \\
\hline
\end{tabular}

${ }^{\mathrm{a}}$ Data in parentheses are $95 \% \mathrm{Cls}$

${ }^{\mathrm{b}}$ Determined with logistic regression analysis

goal for early stage ANFH is to preserve the femoral head rather than replace it [30]. Multiple small-diameter drilling has been widely employed for the treatment of ANFH since Kim et al. proposed its use in 2003; however, its efficacy remains controversial (Table 4), with $30-40 \%$ of patients suffering clinical failure $[6,28,31]$. To improve the clinical outcome of multiple small drilling for core decompression, several adjunctive methods have been added following the procedure. Kang et al. administered systemic alendronate as a femoral head-preserving method in ANFH; the clinical success rates in patients with stage II or stage III disease increased by 11.5 and $15.3 \%$, respectively, at a minimum of 4 years follow-up [29]. However, in research conducted by Lim et al., stem cell implantation after multiple drilling did not improve the clinical outcome compared with the conventional method of core decompression (57 \% vs $54.8 \%$ ) at 5-year follow-up [32]. In this study, systemic administration of simvastatin after multiple drilling significantly improved the overall clinical success rate from 57.7 to $84.4 \%$.

Statins inhibit hydroxymethylglutaryl-coenzyme A reductase, one of the rate-limiting enzymes of the mevalonate pathway, and are widely used for the treatment of hyperlipemia. Recently, statins have been demonstrated to be effective for the prophylaxis of corticosteroidinduced ANFH through counteracting the effects of corticosteroid-induced adipogenesis in bone stem cells and systemic changes in lipid metabolism [14, 16, 33, 34]. However, until now it was unknown whether statins can improve the clinical outcome in non-corticosteroidinduced ANFH. Our results show that simvastatin might increase the clinical success rate in non-steroid induced ANFH. There may be several possible mechanisms for this effect. (1) Promotion of bone formation: By inhibiting the mevalonate pathway and preventing the prenylation and function of small GTPases, BMP-2 expression may be stimulated, causing increased osteoblast expression and differentiation and subsequent enhancement of bone formation [35]. (2) Inhibition of bone absorption: By suppressing cellular membrane fusion events [36] and the RANKL signaling system [19], formation of osteoclasts could be inhibited and, by inhibiting of the mevalonate pathway [37], osteoclast function might be affected. (3) Recovery of blood supply: Simvastatin could promote the proliferation of vascular endothelial cells through stimulating the release of vascular endothelial growth factor, promoting recovery of the blood supply to the necrotic area [38].

Several studies have demonstrated that the clinical outcome of osteonecrosis of the femoral head is associated with the stage of the disease $[8,28,29]$. Early disease has a better clinical outcome. In agreement with these studies, we achieved excellent results in hips with earlier stage disease. Our results confirm that BMI can serve as a valuable parameter for the evaluation of clinical outcome. Patients with a higher BMI might have a more rapidly

Table 4 Literature review

\begin{tabular}{|c|c|c|c|c|c|c|}
\hline \multirow[t]{2}{*}{ Study } & \multirow[t]{2}{*}{ Treatment } & \multicolumn{3}{|c|}{ Success rate } & \multirow{2}{*}{$\begin{array}{l}\text { Follow-up } \\
\text { (months) }\end{array}$} & \multirow{2}{*}{$\begin{array}{l}\text { Overall } \\
\text { success rate }\end{array}$} \\
\hline & & I & $\|$ & III & & \\
\hline Song et al. & Multi-drilling CD & $79.5 \%$ & $76.6 \%$ & $34.9 \%$ & $87(60-134)$ & $66.3 \%$ \\
\hline Mont et al. & Multi-drilling CD & $80 \%$ & $57 \%$ & - & $24(20-39)$ & $71 \%$ \\
\hline Kang et al. & Multi-drilling CD & - & $79 \%$ & $46.2 \%$ & $62(49-71)$ & $71.2 \%$ \\
\hline Lee et al. & Multi-drilling CD & $100 \%$ & $65 \%$ & $40 \%$ & $37.1(24-60)$ & $56 \%$ \\
\hline Our research & Multi-drilling CD & $85.7 \%$ & $56.2 \%$ & - & 36 & $57.7 \%$ \\
\hline Omran et al. & Multi-drilling CD & $100 \%$ & $66.7 \%$ & - & At least 24 & $72.7 \%$ \\
\hline Kang et al. & Multi-drilling CD + alendronate & - & $90.5 \%$ & $61.5 \%$ & $63(48-75)$ & $83.6 \%$ \\
\hline Lim et al. & Multi-drilling CD + stem cell & - & $60.8 \%$ & $42.9 \%$ & 60 & $53.9 \%$ \\
\hline Our research & Multi-drilling CD + simvastatin & $100 \%$ & $82.6 \%$ & - & 36 & $81.5 \%$ \\
\hline
\end{tabular}


progressive form of the disease. Although several studies have suggested that clinical outcomes are worse in patients with corticosteroid-related osteonecrosis $[8,39,40]$, in the present study the clinical outcome was unrelated to corticosteroid use. Few hips with corticosteroid-related osteonecrosis in this study might explain this discrepancy.

Our study has several limitations. First, this was a retrospective study with a small number of individuals. A large scale randomized controlled trial is essential to evaluate the clinical efficacy of the treatment. Second, the follow-up period was short, with observations truncated 36 months postoperatively. Studies show that most clinical failures occur within 3 years postoperatively $[8,11]$, but a longer follow-up period will still be needed in the future. Third, the simvastatin regimen was chosen according to that used to treat osteoporosis [41]. The optimal dose and duration of simvastatin treatment remain to be determined.

\section{Conclusion}

Despite these shortcomings, from the results of our research it seems reasonable to assume that simvastatin can enhance the effects of multiple decompressions in preventing the progression of ANFH and reducing the risk of femoral head collapse. Long term results and greater numbers of patients are needed to make definitive conclusions.

\section{Abbreviations \\ ANFH, Avascular necrosis of the femoral head; ARCO, Association Internationale de Recherche sur la Circulation Osseuse; BMI, Body mass index; BMP-2, Bone morphogenetic protein 2; HHS, Harris Hip Score; MRI, Magnetic resonance imaging}

\section{Acknowledgements}

We should give special thanks to Haitao Sun, Chuanchen Zhang and Jinfa Xu of Radiology Department in Liaocheng People Hospital for his crucial help on the MRI scans and plain radiographs evaluation and measurement.

\section{Funding}

This work was supported by the Natural Science Foundation of Shandong Province (ZR2014HL026), and the Medical and Health Development Plan of Shandong Province (2014WS0293). The funders played an important role in the design of the study, data collection and analysis, interpretation of data, and in writing the manuscript.

\section{Availability of data and materials}

The datasets supporting the conclusions of this article are not available in an open access repository because the authors have not finished the data analysis yet. If anyone is interested in exploring specific issue, please contact Prof. Zhenfeng Yuan.

\section{Authors' contributions}

HY participated in the acquisition of data, interpretation of data and drafted the manuscript. ZFY conceived of the study, and participated in its design and coordination and helped to draft the manuscript. DWW performed the statistical analysis. All authors read and approved the final manuscript.

\section{Competing interests}

The authors declare that they have no competing interests.

\section{Consent to publish}

Figure 2 was authorized to publish by patient.

\section{Ethics approval and consent to participate}

This study was approved by the ethics committee of Liaocheng People's Hospital (201213) and was carried out in accordance with the Declaration of Helsinki. The participants provided written informed consent to participate in this research.

Received: 25 March 2016 Accepted: 3 August 2016

Published online: 15 August 2016

\section{References}

1. Musso ES, Mitchell SN, Schink-Ascani M, Bassett CA. Results of conservative management of osteonecrosis of the femoral head. A retrospective review. Clin Orthop Relat Res. 1986;207:209-15.

2. Martin JR, Houdek MT, Sierra RJ. Use of concentrated bone marrow aspirate and platelet rich plasma during minimally invasive decompression of the femoral head in the treatment of osteonecrosis. Croat Med J. 2013;54(3):219-24.

3. Markel DC, Miskovsky C, Sculco TP, Pellicci PM, Salvati EA. Core decompression for osteonecrosis of the femoral head. Clin Orthop Relat Res. 1996;323:226-33.

4. Moya-Angeler J, Gianakos AL, Villa JC, Ni A, Lane JM. Current concepts on osteonecrosis of the femoral head. World J Orthop. 2015;6(8):590-601.

5. Scully SP, Aaron RK, Urbaniak JR. Survival analysis of hips treated with core decompression or vascularized fibular grafting because of avascular necrosis. J Bone Joint Surg Am. 1998;80(9):1270-5.

6. Song WS, Yoo JJ, Kim YM, Kim HJ. Results of multiple drilling compared with those of conventional methods of core decompression. Clin Orthop Relat Res. 2007:454:139-46.

7. Rastogi S, Sankineani SR, Nag HL, Mohanty S, Shivanand G, Marimuthu K, Kumar R, Rijal L. Intralesional autologous mesenchymal stem cells in management of osteonecrosis of femur: a preliminary study. Musculoskelet Surg. 2013;97(3):223-8.

8. Bozic KJ, Zurakowski D, Thornhill TS. Survivorship analysis of hips treated with core decompression for nontraumatic osteonecrosis of the femoral head. J Bone Joint Surg Am. 1999:81(2):200-9.

9. Mihalko WM, Balos L, Santilli M, Mindell ER. Osteonecrosis after powered core decompression. Clin Orthop Relat Res. 2003;412:77-83.

10. Mont MA, Carbone JJ, Fairbank AC. Core decompression versus nonoperative management for osteonecrosis of the hip. Clin Orthop Relat Res. 1996;324:169-78.

11. Calori GM, Mazza E, Colombo M, Mazzola S, Mineo GV, Giannoudis PV. Treatment of AVN using the induction chamber technique and a biological-based approach: indications and clinical results. Injury. 2014:45(2):369-73.

12. Kim SY, Kim DH, Park IH. Multiple drilling compared with core decompression for the treatment of osteonecrosis of the femoral head. J Bone Joint Surg Am. 2004;86B(Suppl):149.

13. Pritchett JW. Statin therapy decreases the risk of osteonecrosis in patients receiving steroids. Clin Orthop Relat Res. 2001;386:173-8.

14. Nishida K, Yamamoto T, Motomura G, Jingushi S, Iwamoto Y. Pitavastatin may reduce risk of steroid-induced osteonecrosis in rabbits: a preliminary histological study. Clin Orthop Relat Res. 2008:466(5):1054-8.

15. Ajmal M, Matas AJ, Kuskowski M, Cheng EY. Does statin usage reduce the risk of corticosteroid-related osteonecrosis in renal transplant population? Orthop Clin North Am. 2009:40(2):235-9.

16. Jiang Y, Zhang Y, Zhang H, Zhu B, Li P, Lu C, Xu Y, Chen W, Lin N. Pravastatin prevents steroid-induced osteonecrosis in rats by suppressing PPARgamma expression and activating Wnt signaling pathway. Exp Biol Med (Maywood). 2014;239(3):347-55.

17. Mundy G, Garrett R, Harris S, Chan J, Chen D, Rossini G, Boyce B, Zhao M, Gutierrez $\mathrm{G}$. Stimulation of bone formation in vitro and in rodents by statins. Science. 1999;286(5446):1946-9.

18. Sugiyama M, Kodama T, Konishi K, Abe K, Asami S, Oikawa S. Compactin and simvastatin, but not pravastatin, induce bone morphogenetic protein-2 in human osteosarcoma cells. Biochem Biophys Res Commun. 2000;271(3):688-92.

19. Ahn KS, Sethi G, Chaturvedi MM, Aggarwal BB. Simvastatin, 3-hydroxy-3-methylglutaryl coenzyme A reductase inhibitor, suppresses osteoclastogenesis induced by receptor activator of nuclear factor-kappaB ligand through modulation of NF-kappaB pathway. Int J Cancer. 2008;123(8):1733-40. 
20. Ayukawa Y, Yasukawa E, Moriyama Y, Ogino Y, Wada H, Atsuta I, Koyano K. Local application of statin promotes bone repair through the suppression of osteoclasts and the enhancement of osteoblasts at bone-healing sites in rats. Oral Surg Oral Med Oral Pathol Oral Radiol Endod. 2009;107(3):336-42.

21. Bauer DC, Mundy GR, Jamal SA, Black DM, Cauley JA, Ensrud KE, van der Klift M, Pols HA. Use of statins and fracture: results of 4 prospective studies and cumulative meta-analysis of observational studies and controlled trials. Arch Intern Med. 2004;164(2):146-52.

22. Edwards CJ, Hart DJ, Spector TD. Oral statins and increased bone-mineral density in postmenopausal women. Lancet. 2000;355(9222):2218-9.

23. Chan MH, Mak TW, Chiu RW, Chow CC, Chan IH, Lam CW. Simvastatin increases serum osteocalcin concentration in patients treated for hypercholesterolaemia. J Clin Endocrinol Metab. 2001;86(9):4556-9.

24. Liu Y, Liu S, Su X. Core decompression and implantation of bone marrow mononuclear cells with porous hydroxylapatite composite filler for the treatment of osteonecrosis of the femoral head. Arch Orthop Trauma Surg. 2013;133(1):125-33.

25. ARCO Committee on Terminology and Staging. In: Schoutens AAJ, Gardeniers JWM, Hughes SPF, editors. Bone circulation and vascularization in normal and pathological conditions. New York, NY: Plenum Press; 1993. p. 375-80.

26. Kim YM, Ahn JH, Kang HS, Kim HJ. Estimation of the extent of osteonecrosis of the femoral head using MRI. J Bone Joint Surg (Br). 1998;80(6):954-8.

27. Sugano N, Atsumi T, Ohzono K, Kubo T, Hotokebuchi T, Takaoka K. The 2001 revised criteria for diagnosis, classification, and staging of idiopathic osteonecrosis of the femoral head. J Orthop Sci. 2002;7(5):601-5.

28. Lee MS, Hsieh PH, Chang YH, Chan YS, Agrawal S, Ueng SW. Elevated intraosseous pressure in the intertrochanteric region is associated with poorer results in osteonecrosis of the femoral head treated by multiple drilling. J Bone Joint Surg (Br). 2008;90(7):852-7.

29. Kang P, Pei F, Shen B, Zhou Z, Yang J. Are the results of multiple drilling and alendronate for osteonecrosis of the femoral head better than those of multiple drilling? A pilot study. Joint Bone Spine. 2012;79(1):67-72.

30. Yang P, Bian C, Huang X, Shi A, Wang C, Wang K. Core decompression in combination with nano-hydroxyapatite/polyamide 66 rod for the treatment of osteonecrosis of the femoral head. Arch Orthop Trauma Surg. 2014:134(1):103-12.

31. Mont MA, Ragland PS, Etienne G. Core decompression of the femoral head for osteonecrosis using percutaneous multiple small-diameter drilling. Clin Orthop Relat Res. 2004;429:131-8.

32. Lim YW, Kim YS, Lee JW, Kwon SY. Stem cell implantation for osteonecrosis of the femoral head. Exp Mol Med. 2013;45:e61.

33. Nozaki Y, Kumagai K, Miyata N, Niwa M. Pravastatin reduces steroid-induced osteonecrosis of the femoral head in SHRSP rats. Acta Orthop. 2012;83(1):87-92.

34. Pengde K, Fuxing $P$, Bin $S$, Jing $Y$, Jingqiu C. Lovastatin inhibits adipogenesis and prevents osteonecrosis in steroid-treated rabbits. Joint Bone Spine. 2008;75(6):696-701.

35. Jadhav SB, Jain GK. Statins and osteoporosis: new role for old drugs. J Pharm Pharmacol. 2006:58(1):3-18.

36. Sato T, Morita I, Murota S. Involvement of cholesterol in osteoclast-like cell formation via cellular fusion. Bone. 1998;23(2):135-40.

37. Hughes A, Rogers MJ, Idris Al, Crockett JC. A comparison between the effects of hydrophobic and hydrophilic statins on osteoclast function in vitro and ovariectomy-induced bone loss in vivo. Calcif Tissue Int. 2007;81(5):403-13.

38. Takenaka M, Hirade K, Tanabe K, Akamatsu S, Dohi S, Matsuno H, Kozawa O. Simvastatin stimulates VEGF release via p44/p42 MAP kinase in vascular smooth muscle cells. Biochem Biophys Res Commun. 2003;301(1):198-203.

39. Veillette CJ, Mehdian H, Schemitsch EH, McKee MD. Survivorship analysis and radiographic outcome following tantalum rod insertion for osteonecrosis of the femoral head. J Bone Joint Surg Am. 2006;88 Suppl 3:48-55.

40. Mont MA, Fairbank AC, Petri M, Hungerford DS. Core decompression for osteonecrosis of the femoral head in systemic lupus erythematosus. Clin Orthop Relat Res. 1997:334:91-7.

41. Tikiz C, Tikiz H, Taneli F, Gumuser G, Tuzun C. Effects of simvastatin on bone mineral density and remodeling parameters in postmenopausal osteopenic subjects: 1-year follow-up study. Clin Rheumatol. 2005;24(5):447-52.

\section{Submit your next manuscript to BioMed Central and we will help you at every step:}

- We accept pre-submission inquiries

- Our selector tool helps you to find the most relevant journal

- We provide round the clock customer support

- Convenient online submission

- Thorough peer review

- Inclusion in PubMed and all major indexing services

- Maximum visibility for your research

Submit your manuscript at www.biomedcentral.com/submit
) Biomed Central 